\title{
Metal-catalysed organic transformations in water: From bromination to polymerisation
}

\author{
MANISH BHATTACHARJEE* and BRAJA N PATRA \\ Department of Chemistry, Indian Institute of Technology, Kharagpur 721302 \\ e-mail: mxb@iitkgp.ac.in
}

\begin{abstract}
Reaction of $\alpha, \beta$-unsaturated aromatic carboxylic acids with $\mathrm{KBr}$ and $\mathrm{H}_{2} \mathrm{O}_{2}$ in the presence of $\mathrm{Na}_{2} \mathrm{MoO}_{4} \cdot 2 \mathrm{H}_{2} \mathrm{O}$ in aqueous medium affords $\beta$-bromo alkenes in high yields. Metallocene dichlorides, $\mathrm{Cp}_{2} \mathrm{MCl}_{2}(\mathrm{M}=\mathrm{Ti}, \mathrm{Zr}$, or $\mathrm{V})$ catalyse polymerisation of olefins in aqueous medium to afford high molecular weight polymers with low molecular weight distribution.
\end{abstract}

Keywords. Aqueous medium; bromination; polymerisation; titanium; zirconium; vanadium.

\section{Introduction}

Water as a reaction medium has attracted a great deal of attention in recent years. This is because water as a solvent has high heat capacity, high polarity, and is not-miscible with most organic solvents. These properties make water a unique solvent. Due to increasing environmental concerns aqueous phase reactions are becoming more and more popular. ${ }^{1}$ In recent years, a large number of reports have appeared on metal catalysed polymerisation in aqueous medium. ${ }^{2}$ These reports involve mainly late transition metal catalysts. $^{2}$ One of the major problems in the use of late transition metal catalysts is the ease of $\beta$ hydride elimination, which typically competes with chain growth and affords low molecular weight polymers. ${ }^{2 a}$ The use of early transition metal catalysts is expected to afford high molecular weight polymers. However, owing to their extreme moisture sensitivity, the use of early transition metal organometallic compounds as polymerisation catalysts in aqueous medium still poses a challenge.

As a part of our exploration of transition metal catalysed aqueous medium organic transformations, we have been exploring transition metal-catalysed electrophilic bromination of organic substrates ${ }^{3}$ and polymerisation of olefins in aqueous medium. ${ }^{4}$ In this paper we present the results of our studies on early transition metal catalysed aqueous polymerisations of olefins and electrophilic bromination of organic substrates.

\footnotetext{
*For correspondence
}

\section{Results and discussion}

\subsection{Sodium molybdate catalysed aqueous Hunsdiecker reaction}

The classical Hunsdiecker reaction and its later modifications are efficient in the syntheses of organic halides. ${ }^{5}$ However, these reactions have major limitations, such as toxicity and hazards involving the use of elemental bromine, salts of $\mathrm{Hg}(\mathrm{II}), \mathrm{Tl}(\mathrm{I})$, $\mathrm{Pb}(\mathrm{IV}), \mathrm{Ag}(\mathrm{I})$. Apart from this, very poor yields of the products are obtained in the cases of $\alpha, \beta$-unsaturated aromatic carboxylic acids. Recently, some of these difficulties have been overcome by the use of lithium acetate as the catalyst and N-bromosuccinimide as the bromine source, the reaction medium being aqueous acetonitrile. ${ }^{6}$ However, low yields were obtained in the cases of $\alpha, \beta$-unsaturated aromatic carboxylic acids bearing electron-withdrawing groups in the aromatic ring.

Transition metal peroxo compounds have been shown to be efficient oxidizing agents for various organic substrates. ${ }^{7}$ Some marine organismsuse vanadium-dependent enzyme, bromoperoxi-dase, for the bromination of organic compounds using inorganic bromides and hydrogen peroxide. ${ }^{8}$ We have been investigating bromination of organic compounds using vanadium (V) or molybdenum(VI), potasium bromide, and hydrogen peroxide in aqueous medium. ${ }^{3}$ It was observed that transition metal peroxo complexes can oxidize inorganic bromide and produce $\mathrm{Br}_{3}^{-}$species which is in equilibrium with $\mathrm{HOBr}$ and $\mathrm{Br}_{2}$. We thought that this biomimetic system can be utilized as an alternative route to the Hunsdiecker reaction. 
Thus, when $\alpha, \beta$-unsaturated aromatic carboxylic acid is stirred with $\mathrm{KBr}$ and $\mathrm{Na}_{2} \mathrm{MoO}_{4} \cdot 2 \mathrm{H}_{2} \mathrm{O}$ in water and $\mathrm{H}_{2} \mathrm{O}_{2}$ is added dropwise, rapid reaction takes place and after $20 \mathrm{~min}$ of stirring, the corresponding $\beta$-bromo-styrene is obtained in good yield (scheme 1). ${ }^{9}$

It has been shown earlier that $\mathrm{MoO}_{4}^{2-}$ forms a number of peroxo species in solution in the presence of $\mathrm{H}_{2} \mathrm{O}_{2}$. The $\mathrm{pH}$ of the solution of $\mathrm{Na}_{2} \mathrm{MoO}_{4}(0 \cdot 001$ mol) in $\mathrm{H}_{2} \mathrm{O}_{2}\left(15 \mathrm{~cm}^{3}\right)$ is basic in nature, $\mathrm{pH}$ being around 8 . We have noted that, below this $\mathrm{pH}$, the yield of the product is not very good. Thus it is clear that for the reaction a basic medium is required. The ${ }^{95} \mathrm{Mo}$ NMR spectra of a solution of $\mathrm{Na}_{2} \mathrm{MoO}_{4}$ $(0.001 \mathrm{M})$ in $\mathrm{H}_{2} \mathrm{O}_{2}\left(15 \mathrm{~cm}^{3}\right)$ shows a major signal at $-336 \mathrm{ppm}$ and a relatively low intensity signal at $-509 \mathrm{ppm}$. These are due to the formation of $\left[\mathrm{MoO}\left(\mathrm{O}_{2}\right)_{3}\right]^{2-}$ and $\left[\mathrm{Mo}\left(\mathrm{O}_{2}\right)_{4}\right]^{2-}$ species, respectively. ${ }^{10}$ Upon addition of $\mathrm{Br}^{-}$both the signals at -509 and $-336 \mathrm{ppm}$ disappear and two signals appear at -222 and $-37 \mathrm{ppm}$. The signal at $-222 \mathrm{ppm}$ can be assigned to $\left[\mathrm{MoO}\left(\mathrm{O}_{2}\right)_{2}\right]^{2-} .{ }^{10}$ The signal at $-37 \mathrm{ppm}$ may be assigned to a molybdate species coordinated to bromide. The slight shift in the observed ${ }^{95} \mathrm{Mo}$ NMR spectra from those of reported ones ${ }^{10}$ may be due to the effect of $\mathrm{pH}$ as well as extent of hydration.

A blank reaction, that is a similar reaction without adding $\mathrm{Na}_{2} \mathrm{MoO}_{4}$, did not afford the brominated products. Thus, it is clear that, bromide is oxidized by the peroxomolybdate species formed in solution.

The electronic spectrum of a solution $\left(10^{-3} \mathrm{M}\right)$ of $\mathrm{Na}_{2} \mathrm{MoO}_{4}$ in $\mathrm{H}_{2} \mathrm{O}_{2}\left(2 \times 10^{-2} \mathrm{M}\right)$ shows bands at 445 $(\varepsilon=162)$ and at $293 \mathrm{~nm}(\varepsilon=1620)$. These are due to the tetraperoxo and triperoxomolybdate species. ${ }^{10}$ When $\mathrm{KBr}$ is added to this solution an absorbance increase is observed in the region 700 to $290 \mathrm{~nm}$. However, no new band appears. The molar extinction coefficient of the $445 \mathrm{~nm}$ band increases to 320 and the band at $293 \mathrm{~nm}$ shifts to $298 \mathrm{~nm}$ with increase in the molar extinction coefficient $(\varepsilon=1833)$. It may be noted that the oxidized bromide species, $\mathrm{Br}_{2}, \mathrm{Br}_{3}^{-}$ and $\mathrm{OBr}^{-}$, absorb in the region, 450 to $300 \mathrm{~nm}$. It is clear that the peroxomolybdate generated from the

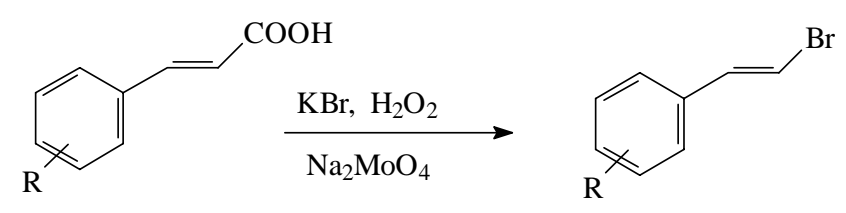

$\mathrm{R}=4$ or $4-\mathrm{Ome}$ or $4-\mathrm{Cl}$ or $2-\mathrm{Me}$ or $2-\mathrm{Cl}$ reaction of $\mathrm{H}_{2} \mathrm{O}_{2}$ and $\mathrm{MoO}_{4}^{2-}$ reacts with $\mathrm{Br}^{-}$to produce an equilibrium mixture of $\mathrm{Br}_{2}, \mathrm{Br}_{3}^{-}$, and $\mathrm{OBr}^{-}$, which then react with the unsaturated acid to give bromoalkene (scheme 2).

\section{$2.2 \mathrm{Cp}_{2} \mathrm{TiCl}_{2}$ and $\mathrm{Cp}_{2} \mathrm{ZrCl}_{2}$ catalysed homo- polymerisation of styrene and methylmethacrylate}

Aqueous catalytic polymerisation seems like a contradiction at first sight because of the high moisture sensitivity of the Ziegler-Natta catalysts. However, there is a strong commercial and environmental driving force to develop aqueous routes to polyolefin with the desired property. ${ }^{11}$ Free radical initiated emulsion polymerisation of olefins is well known. A large numbers of reports have appeared on the catalytic systems capable of polymerisation in aqueous medium involving mainly late transition metal catalysts. $^{2}$ A recent report deals with syndiospecific polymerisation of styrene in water-toluene biphasic medium using $\left[\left(\mathrm{C}_{5} \mathrm{Me}_{5}\right) \mathrm{Ti}(\mathrm{OMe})_{3}\right]$ catalyst along with a borate and an alkylaluminium compound as activators and cationic or neutral surfactant as emulsifier. $^{2 \mathrm{e}}$ Development of an early transition metal based catalyst system for polymerisation of olefin in aqueous medium without using any organic solvent or any activator such as MAO or other alkyl aluminum compounds or borate still remains a challenge.

It has already been shown that, in the homogeneous Ziegler-Natta catalyst, $\left[\mathrm{Cp}_{2} \mathrm{MMe}\right]^{+}(\mathrm{M}=\mathrm{Ti}$ or $\mathrm{Zr}$ ) is responsible for stereospecific polymerisation. ${ }^{12}$ It is also well known that, $\mathrm{Cp}_{2} \mathrm{MCl}_{2}$ when dissolved in water, gives $\left[\mathrm{Cp}_{2} \mathrm{M}\left(\mathrm{H}_{2} \mathrm{O}\right) \mathrm{Cl}\right]^{+},\left[\mathrm{Cp}_{2} \mathrm{M}\left(\mathrm{H}_{2} \mathrm{O}\right)_{2}\right]^{2+}$,

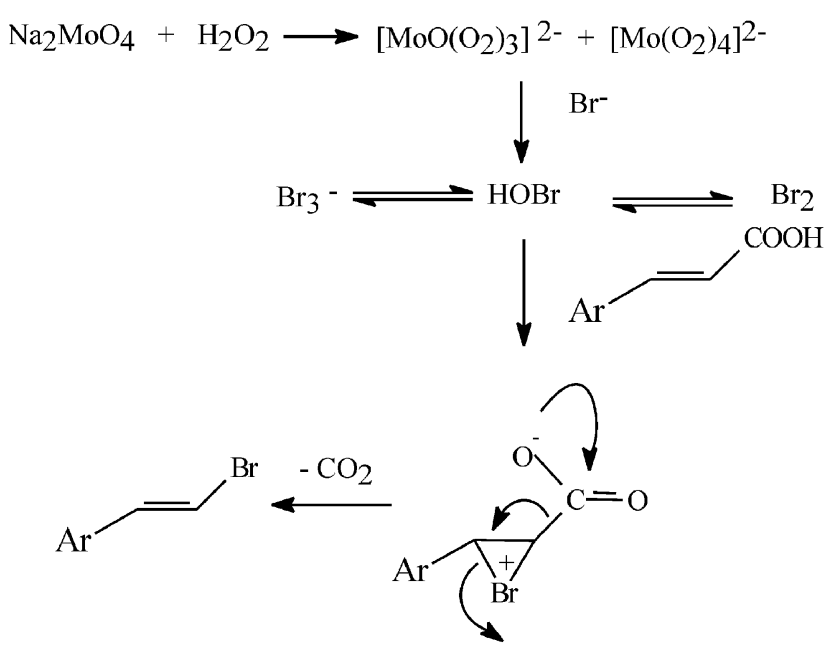

Scheme 2.

Scheme 1. 
and $\left[\mathrm{Cp}_{2} \mathrm{M}(\mathrm{OH})\right]^{+}$in solution as major products. ${ }^{13}$ Our general synthetic approach is in situ formation of $\left[\mathrm{Cp}_{2} \mathrm{M}(\mathrm{OH})\right]^{+}$from aqueous solution of $\mathrm{Cp}_{2} \mathrm{MCl}_{2}$ and stabilization of this cation by large, soft and noncoordinating anion, $n$-dodecyl sulphate, and utilization of $\left[\mathrm{Cp}_{2} \mathrm{Ti}(\mathrm{OH})\right]^{+}$as polymerisation catalyst. Sodium $n$-dodecyl sulphate (SDS) is expected to play the dual role of stabilizer of the cation as well as an emulsifying agent for the monomer.

Accordingly, homo-polymerisation of styrene $e^{4 a, 4 c}$ and methylmethacrylate (MMA) ${ }^{4 \mathrm{~b}, 4 \mathrm{c}}$ was carried out in aqueous medium in the presence of SDS and one mole percent of catalysts, $\mathrm{Cp}_{2} \mathrm{MCl}_{2}\left(\mathrm{M}=\mathrm{Ti}^{\mathrm{4a}, 4 \mathrm{~b}}\right.$ or $\mathrm{Zr}^{4 \mathrm{c}}$ ). The details of the results are given in tables 1 and 2. The average molecular weights of the polystyrene (PS) and poly(methylmethacrylate) (PMMA), measured by GPC (against standard polystyrene.) lies in the range 690,000 to 540,000 and 739,000 to 514,000 , respectively. On an average $M_{w} / M_{n}$ ratio is found to be 1.7 and 1.6 , respectively, which is fairly narrow and is indicative of a single site catalyst. ${ }^{14}$ The molecular weights are much higher then the ordinary commercially available PS or PMMA. The homo-polymers obtained were characterized by dif- ferential scanning calorimetry (DSC), ${ }^{1} \mathrm{H}$, and ${ }^{13} \mathrm{C}$ NMR, and IR spectroscopy. The DSC measurements, ${ }^{1} \mathrm{H}$, and ${ }^{13} \mathrm{C}$ NMR of PS clearly established the atactic nature of the polymer. The relative ratio of the triads $[r r],[m r],[\mathrm{mm}]$ in PMMA was found to be $60: 38: 2$ from ${ }^{1} \mathrm{H}$ NMR spectra, which is similar to that obtained from radical polymerisation of MMA.

It has been found that the conversion is both temperature and time dependent. In the case of $\mathrm{Cp}_{2} \mathrm{TiCl}_{2}$ catalysed polymerisation of MMA, up to $40^{\circ} \mathrm{C}$ we could not detect any product. The conversion is negligible at $50^{\circ} \mathrm{C}$. The highest conversion was observed at $70^{\circ} \mathrm{C}$, and the conversion drops dramatically at the temperature $90^{\circ} \mathrm{C}$. Up to $9 \mathrm{~h}$ of reaction time we could observe only little polymerisation. After $9 \mathrm{~h}$ of reaction time the yield increases steadily rises to a maximum at the reaction time of $11 \mathrm{~h}$. In the case of $\mathrm{Cp}_{2} \mathrm{TiCl}_{2}$ catalysed styrene polymerisation, maximum conversion is observed at the reaction time of $6 \mathrm{~h}$ and up to $30^{\circ} \mathrm{C}$ no polymerisation takes place. At $50^{\circ} \mathrm{C}$, the conversion is found to be highest and the conversion drops with further increase in tempe rature. Similarly, in $\mathrm{Cp}_{2} \mathrm{ZrCl}_{2}$ catalysed polymerisations, up to $40^{\circ} \mathrm{C}$ we could not detect any product.

Table 1. Polymerisation of $\mathrm{MMA}$ and styrene with $\mathrm{Cp}_{2} \mathrm{TiCl}_{2}$ at different temperature using different surfactant $\mathrm{t}^{\mathrm{a}}$.

\begin{tabular}{lcccccccc}
\hline $\begin{array}{l}\mathrm{Cp}_{2} \mathrm{TiCl}_{2} \\
(\mathrm{~mol})\end{array}$ & $\begin{array}{c}\text { MMA } \\
(\mathrm{mol})\end{array}$ & $\begin{array}{c}\text { Styrene } \\
(\mathrm{mol})\end{array}$ & $\begin{array}{c}\text { Surfactant } \\
\left(\times 10^{-3} \mathrm{~mol}\right)\end{array}$ & $T\left({ }^{\circ} \mathrm{C}\right)$ & $M_{w}$ & $M_{n}$ & $M_{w} / M_{n}$ & Yield $(\%)$ \\
\hline 0.0005 & $0 \cdot 05$ & & SDS $(1 \cdot 6)$ & 70 & 514,000 & 321,250 & $1 \cdot 6$ & $70^{\mathrm{b}}$ \\
$0 \cdot 0005$ & $0 \cdot 05$ & & SDS $(1 \cdot 6)$ & 90 & 739,000 & 461,875 & $1 \cdot 6$ & $20^{\mathrm{b}}$ \\
$0 \cdot 0005$ & & 0.05 & SDS $(1 \cdot 6)$ & 50 & 540,000 & 300,000 & $1 \cdot 8$ & $73^{\mathrm{c}}$ \\
$0 \cdot 0005$ & & $0 \cdot 05$ & SDS $(1 \cdot 6)$ & 70 & 688,000 & 404,705 & $1 \cdot 7$ & $46 \cdot 2^{\mathrm{c}}$ \\
$0 \cdot 0005$ & & 0.05 & SDS $(1 \cdot 6)$ & 90 & 690,000 & 405,880 & $1 \cdot 7$ & $5 \cdot 8^{\mathrm{c}}$ \\
$0 \cdot 0005$ & & 0.05 & CTAB (1.6) & 70 & & - & - & - \\
$0 \cdot 0005$ & & 0.05 & - & 70 & & - & - & - \\
- & & 0.05 & SDS (1.6) & 70 & & - & - & - \\
\hline
\end{tabular}

${ }^{\mathrm{a}} T=$ polymerisation temperature; $M_{w}=$ molecular weight $(\mathrm{GPC}) ; \mathrm{MMA} / \mathrm{styrene}$ concentration $=0.5 \mathrm{~mol} / \mathrm{l}$ $[\mathrm{Ti}]=0.005 \mathrm{~mol} / \mathrm{l} .{ }^{\mathrm{b}}$ Reaction time $=11 \mathrm{~h} .{ }^{\mathrm{c}}$ Reaction time $=6 \mathrm{~h}$

Table 2. Polymerisation of MMA and styrene with $\mathrm{Cp}_{2} \mathrm{ZrCl}_{2}$ at different temperature using SDS .

\begin{tabular}{lcccccccc}
\hline $\begin{array}{l}\mathrm{Cp}_{2} \mathrm{TiCl}_{2} \\
(\mathrm{~mol})\end{array}$ & $\begin{array}{c}\text { MMA } \\
(\mathrm{mol})\end{array}$ & $\begin{array}{c}\text { Styrene } \\
(\mathrm{mol})\end{array}$ & $\begin{array}{c}\text { Surfactant } \\
\left(\times 10^{-3} \mathrm{~mol}\right)\end{array}$ & $T\left({ }^{\circ} \mathrm{C}\right)$ & $M_{w}$ & $M_{n}$ & $M_{w} / M_{n}$ & Yield $(\%)$ \\
\hline 0.0005 & $0 \cdot 05$ & & SDS $(1 \cdot 6)$ & 70 & 781200 & 564300 & $1 \cdot 4$ & $20 \cdot 0^{\mathrm{b}}$ \\
$0 \cdot 0005$ & $0 \cdot 05$ & & SDS $(1 \cdot 6)$ & 90 & 581000 & 462000 & $1 \cdot 3$ & $49 \cdot 0^{\mathrm{b}}$ \\
0.0005 & & 0.05 & SDS $(1 \cdot 6)$ & 70 & 840700 & 582800 & $1 \cdot 4$ & $33 \cdot 5^{\mathrm{c}}$ \\
$0 \cdot 0005$ & & 0.05 & SDS $(1 \cdot 6)$ & 90 & 525600 & 269400 & $1 \cdot 9$ & $84^{\mathrm{c}}$ \\
\hline
\end{tabular}

${ }^{\mathrm{a}} T=$ polymerisation temperature; $M_{w}=$ molecular weight $(\mathrm{GPC}) ; \mathrm{MMA} / \mathrm{styrene}$ concentration $=0.5 \mathrm{~mol} / 1$ $[\mathrm{Zr}]=0.005 \mathrm{~mol} / 1 .{ }^{\mathrm{b}}$ Reaction time $=12 \mathrm{~h} .{ }^{\mathrm{c}}$ Reaction time $=15 \mathrm{~h}$ 
The conversion is negligible at $50^{\circ} \mathrm{C}$. The highest conversion is observed at $90^{\circ} \mathrm{C}$, and the conversion drops dramatically at temperatures above $90^{\circ} \mathrm{C}$. The conversion is also found to be dependent on polymerisation time (table 3 ). Up to $3 \mathrm{~h}$ of reaction time we could observe only slight polymerisation. After $3 \mathrm{~h}$ of reaction time the yield increases steadily rises to a maximum at reaction time of $15 \mathrm{~h}$ in the case of styrene, whereas, in MMA polymerisation, maximum yield is obtained at $12 \mathrm{~h}$ of reaction time. The plot of polymer yield versus time (figure 1) clearly indicates that the active species is stable up to 12 to $15 \mathrm{~h}$. The plot of number-averaged molecular weight $\left(M_{n}\right)$ versus percentage yield (figure 2) clearly shows that the polymerisation is not natural.

Table 3. Time-dependence polymerisation of styrene and methylmethacrylate ${ }^{\mathrm{a}}$.

\begin{tabular}{lcccc}
\hline Monomer & Time (h) & Yield $(\%)$ & $M_{n}$ & $M_{w} / M_{n}$ \\
\hline Styrene & 3 & 5 & $\mathrm{~b}$ & \\
& 5 & 27.26 & 247000 & $1 \cdot 72$ \\
& 10 & $64 \cdot 07$ & 238000 & $1 \cdot 78$ \\
& 15 & 84 & 269400 & $1 \cdot 9$ \\
MMA & 20 & 81.9 & 198000 & $1 \cdot 8$ \\
& 10 & $3 \cdot 5$ & $\mathrm{~b}$ & \\
& 12 & 49 & 462999 & $1 \cdot 25$ \\
& 15 & $25 \cdot 64$ & 401000 & $1 \cdot 26$ \\
& 20 & $34 \cdot 8$ & 562900 & $1 \cdot 8$ \\
& 25 & 36.48 & 484000 & $1 \cdot 2$ \\
\hline
\end{tabular}

${ }^{\text {a }}$ Polymerisation temperature $=90^{\circ} \mathrm{C}$, MMA/styrene concentration $=0.5 \mathrm{~mol} / 1[\mathrm{Zr}]=0.005 \mathrm{~mol} / \mathrm{l} ; \mathrm{b}=$ not determined

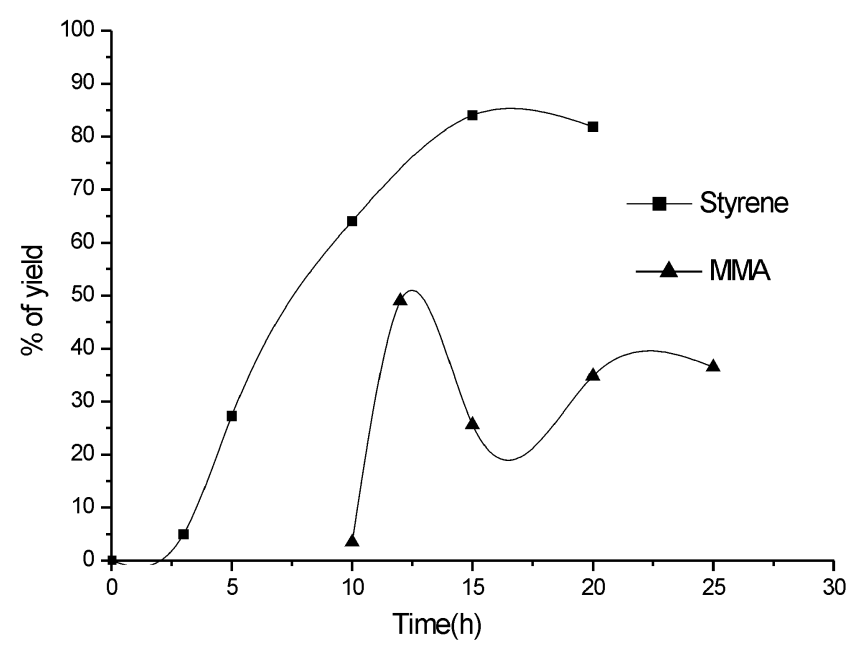

Figure 1. Plot of polymer yield versus polymerisation time ( $\boldsymbol{\square}$ styrene, $\boldsymbol{\Delta}$ MMA).
The observed atactic nature of the polystyrene and the observed triad distribution of PMMA, which is similar to the typical stereo-structure of free radical PMMA led us to believe that, in the present case a free radical polymerisation may be in operation, though, a large number of Ziegler-Natta catalytic systems are known to afford atactic polymers. Attempted polymerisation without the addition of $\mathrm{Cp}_{2} \mathrm{MCl}_{2}$ failed. This clearly shows that $\mathrm{Cp}_{2} \mathrm{MCl}_{2}$ catalyses the polymerisation reactions and that the polymerisation is not spontaneous. Dioxygen is a strong inhibitor for radical polymerisation of styrene ${ }^{15}$ and is known to increase the induction time and decrease the molecular weight of the polymer. ${ }^{15}$ We have carried out polymerisation reactions in the presence of dioxygen and we could neither observe any increase in the induction period, nor observe any major difference in the molecular weight of the polystyrene. Also, we have carried out polymerisation reactions using styrene or methylmethacrylate (MMA) without removing stabilizer (4-tert-butylcatechol and hydroquinone, respectively) and could polymerise both the monomers successfully. However, addition of potassium fluoride or chloride $\left(\mathrm{Zr}: \mathrm{F}^{-} / \mathrm{Cl}^{-}\right.$ratio was maintained at $1: 2$ ) completely inhibits polymerisation. This may be explained by the fact that fluoride/chloride ions destroy the cation and thus inhibit polymerisation. Although, radical mechanism cannot be ruled out completely, all the results are indicative of an insertion mechanism.

\section{$2.3 \mathrm{Cp}_{2} \mathrm{TiCl}_{2}$-catalysed co-polymerisation of styrene and methylmethacrylate}

In order to further probe the mechanism of polymerisation, $\mathrm{Cp}_{2} \mathrm{TiCl}_{2}$-catalysed copolymerisation of MMA and styrene has been carried out ${ }^{4 \mathrm{~d}}$ and the microstructure of the copolymer has been determined from ${ }^{1} \mathrm{H}$ NMR spectroscopy. Also, the reactivite ratios of the monomers have been determined. The details of the results of co-polymerisation are presented in table 4.

It is observed that at MMA:styrene ratio $1: 4$, molecular weight of the copolymer is highest and $M_{w} / M_{n}$ is lowest. As the concentration of MMA is increased in the monomer feed, the incorporation of MMA in the copolymer increases. The ideal feed ratio was determined to be $1: 1$, as in this feed ratio molecular weight of the copolymer was 250,245 with lowest $M_{w} / M_{n}$ ratio $(1: 1)$, and higher yields. 
Table 4. $\mathrm{Cp}_{2} \mathrm{TiCl}_{2}$-catalysed copolymerisation of styrene and methylmethacrylate.

\begin{tabular}{lcccccc}
\hline $\begin{array}{l}\mathrm{Cp}_{2} \mathrm{TiCl}_{2} \\
(\mathrm{~mol})\end{array}$ & $\begin{array}{c}\text { Feed ratio MMA/ } \\
\text { styrene (mol/mol) }\end{array}$ & $\begin{array}{c}\text { Surfactant } \\
\left(\times 10^{-3} \text { mol) }\right.\end{array}$ & $\begin{array}{c}\text { Copolymer composition } \\
(\text { MMA : styrene) })^{\mathrm{b}}\end{array}$ & $M_{w}{ }^{\mathrm{c}}$ & $M_{w} / M_{n}{ }^{\mathrm{c}}$ & ${\text { Yield }(\%)^{\mathrm{d}}}^{\mathrm{d}}$ \\
\hline $0 \cdot 0005$ & $2 \cdot 125: 1$ & SDS $(1 \cdot 6)$ & $1: 0 \cdot 35$ & 195,200 & $1 \cdot 5$ & 35 \\
$0 \cdot 0005$ & $1: 1$ & SDS $(1 \cdot 6)$ & $1: 0 \cdot 57$ & 250,200 & $1 \cdot 1$ & 32 \\
$0 \cdot 0005$ & $0 \cdot 56: 1$ & SDS $(1 \cdot 6)$ & $1: 1 \cdot 02$ & 215,400 & $1 \cdot 3$ & 31 \\
$0 \cdot 0005$ & $0 \cdot 25: 1$ & SDS $(1 \cdot 6)$ & $1: 2$ & 254,800 & $1 \cdot 2$ & 9 \\
\hline
\end{tabular}

${ }^{\mathrm{a}}$ Reaction time $=16 \mathrm{~h}$. Reaction temperature $=70^{\circ} \mathrm{C}$. Total monomer concentration $(\mathrm{MMA}+$ styrene $)=$ $0.5 \mathrm{~mol} / \mathrm{l}[\mathrm{Ti}]=0.005 \mathrm{~mol} / \mathrm{l}$. ${ }^{\mathrm{b}}$ Composition of extracted copolymer obtained from ${ }^{1} \mathrm{H} \mathrm{NMR}$; In mole ${ }^{\mathrm{c}} M_{w}=$ molecular weight (GPC). ${ }^{\mathrm{d}}$ Obtained from total monomer feed and extracted copolymer

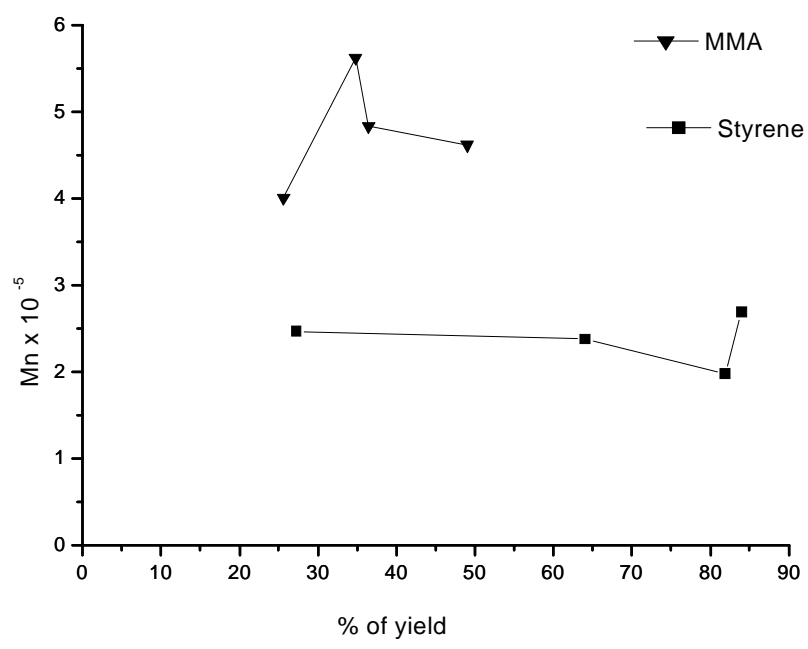

Figure 2. Plot of numbers averaged molecular weight $\left(M_{n}\right)$ versus polymer yield ( $\boldsymbol{\Delta}$ MMA, $\square$ styrene).

A temperature-dependent copolymerisation was done and it was found that up to $50^{\circ} \mathrm{C}$ no polymerisation could be observed the optimum temperature was found to be $70^{\circ} \mathrm{C}$. Similarly, time-dependent copolymerisation study was conducted and optimum time was determined to be $16 \mathrm{~h}$.

The ${ }^{13} \mathrm{C}$ and ${ }^{1} \mathrm{H}$ NMR spectra of the copolymers confirm the random nature of the copolymer. ${ }^{16}$ The FT-IR spectra matches well with those of reported random copolymers. The ${ }^{1} \mathrm{H}$ NMR spectra of the copolymer show signals for the methoxy $\left(-\mathrm{OCH}_{3}\right)$ protons of the enchained MMA units in the region $\delta 2 \cdot 2$ to $\delta 3.6 \mathrm{ppm}$ with the most intense peak at $\delta$ $3.6 \mathrm{ppm}$, integrating as $\sim 70 \%$ of the $\delta 2 \cdot 2-3.6 \mathrm{ppm}$ region. The $3.6 \mathrm{ppm}$ signal is due to cosyndiotactic MMA units. Thus, the ${ }^{1} \mathrm{H}$ NMR studies show clearly that the copolymer contains atactic polystyrene with cosyndiospecifically enchained MMA units and thus is completely different from radical styrene and MMA copolymerisations that usually afford non-stereoregular random copolymers. ${ }^{16}$
For the determination of reactivity ratio, a set of four copolymerisation reactions were conducted using different monomer feed ratios under identical experimental condition, while conversion was restricted to below $10 \%$. The composition of the copolymers was determined from the ${ }^{1} \mathrm{H}$ NMR spectra. The monomer reactivity ratio was determined using the Finemann-Ross method $^{17}$, and found to be $r_{1}=0.385$ and $r_{2}=1.19$. The reactivity ratios are completely different from free radical co-polymerisation. $^{18}$

Reactivity ratios of the monomers as well as the inhibition experiments clearly show that the polymerisation reactions do not proceed by radical mechanism. Also, the low polydispersities of the polymers and copolymers obtained indicates that the catalysts are single-site catalysts. All these results indicate that an insertion mechanism is operative in these cases.

\section{$2.4 \mathrm{Cp}_{2} \mathrm{VCl}_{2}$-catalysed polymerisation of styrene and methylmethacrylate and dramatic effect of dioxygen on the molecular weights and yields of the polymers}

Transition metal complexes have been used for activation of dioxygen and hydrogen peroxide and subsequent oxidation of various substrates. ${ }^{3,7,9,19}$ For example, vanadium (IV) compounds have been shown to transfer electron to exogenous $\mathrm{O}_{2} \cdot{ }^{20} \mathrm{Also}$, it has been shown that $\left[\mathrm{Cp}_{2} \mathrm{~V}(\mathrm{acac})\right]^{+}$cation can initiate $\mathrm{O}_{2}$ dependent peroxidation of lipid, wherein a radical mechanism has been proposed. ${ }^{21} \mathrm{We}$ were interested in exploring activation of dioxygen by $\mathrm{Cp}_{2} \mathrm{VCl}_{2}$, for aqueous emulsion polymerisation.

Thus, polymerisation was initiated by the addition of an aqueous solution of $\mathrm{Cp}_{2} \mathrm{VCl}_{2}$ to aqueous emulsified monomer under aerobic condition. The details of the results of polymerisation are given in table $5 .^{22}$ 
Table 5. Polymerisation of MMA and styrene with $\mathrm{Cp}_{2} \mathrm{VCl}_{2}$ at different temperature using SDS under argon and aerobic atomsphere ${ }^{\mathrm{a}}$.

\begin{tabular}{lcccccc}
\hline $\begin{array}{l}\mathrm{Cp}_{2} \mathrm{VCl}_{2} \\
(\mathrm{~mol})\end{array}$ & $\begin{array}{c}\text { Styrene } \\
(\mathrm{mol})\end{array}$ & $\begin{array}{c}\text { MMA } \\
(\mathrm{mol})\end{array}$ & $T\left({ }^{\circ} \mathrm{C}\right)$ & $\begin{array}{c}\text { Reaction } \\
\text { Atmosphere }\end{array}$ & $\begin{array}{c}M_{w} \\
\left(M_{w} / M_{n}\right)\end{array}$ & Yield $(\%)$ \\
\hline $0 \cdot 0005$ & $0 \cdot 05$ & & 70 & Argon & $33,000(2 \cdot 6)$ & ${ }^{\mathrm{b}} 14 \cdot 4$ \\
$0 \cdot 0005$ & $0 \cdot 05$ & & 70 & Air & $2,59,800(2 \cdot 0)$ & ${ }^{\mathrm{b}} 42 \cdot 3$ \\
$0 \cdot 0005$ & $0 \cdot 05$ & & 90 & Air & $2,70,200(1 \cdot 95)$ & ${ }^{\mathrm{b}} 38 \cdot 4$ \\
$0 \cdot 0005$ & & 0.05 & 70 & Air & $2,54,000(1 \cdot 8)$ & ${ }^{\mathrm{c}} 62 \cdot 2$ \\
$0 \cdot 0005$ & & 0.05 & 90 & Air & $1,32,700(1 \cdot 6)$ & ${ }^{\mathrm{c}} 43 \cdot 6$ \\
\hline
\end{tabular}

${ }^{\mathrm{a}} T=$ polymerisation temperature, $M_{w}=$ molecular weight (GPC, against standard polystyrene), SDS concentration $=1.6 \times 10^{-2} \mathrm{~mol} / 1, \quad \mathrm{MMA} /$ styrene concentration $=0.5 \mathrm{~mol} / 1$, $[\mathrm{V}]=0 \cdot 005 \mathrm{~mol} / \mathrm{l} .{ }^{\mathrm{b}}$ Reaction time $=3 \mathrm{~h} .{ }^{\mathrm{c}}$ Reaction time $=15 \mathrm{~h}$

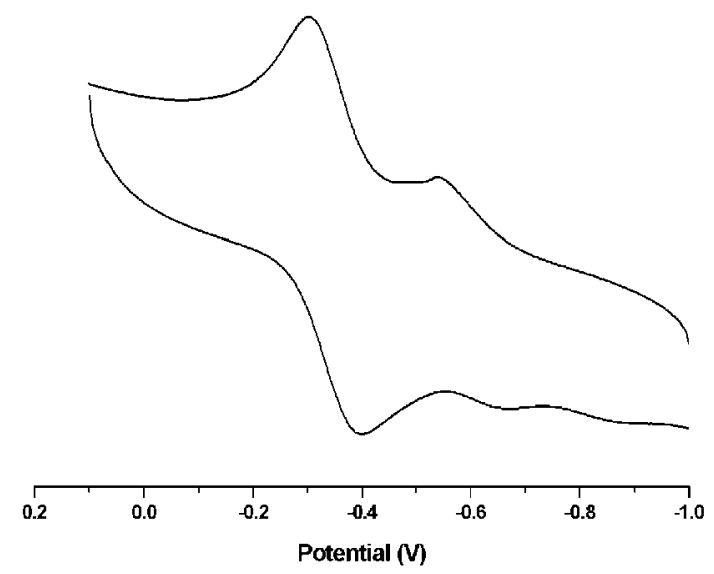

Figure 3. Cyclic voltammogram of the $\mathrm{V}^{\mathrm{IV}} / \mathrm{V}^{\mathrm{V}}$ couple in water of $\mathrm{Cp}_{2} \mathrm{VCl}_{2}$ in the presence of SDS with $\mathrm{Ag} /$ $\mathrm{AgCl}$ reference electrode, glassy carbon working electrode and a platinum wire auxiliary electrode. Scan rate $=0 \cdot 2 \mathrm{~V} / \mathrm{s}$.

The average molecular weights of PMMA, measured by GPC, are high and lie in the range 132,000 to 254,000 . Similarly, the average molecular weights of PS lie in the range 259,000 to 270,600 . The $M_{w} / M_{n}$ ratios are found to lie in the range 1.6 to 2.0 and clearly show low molecular weight distribution and indicate a single-site catalytic system. ${ }^{14}$

It has been shown that in aqueous solution $\mathrm{Cp}_{2} \mathrm{VCl}_{2}$ is converted to a cationic species $\left[\mathrm{Cp}_{2} \mathrm{~V}\right.$ $\left.\left(\mathrm{H}_{2} \mathrm{O}\right)_{2}\right]^{2+}$ which undergoes subsequent hydrolysis to $\left[\mathrm{Cp}_{2} \mathrm{~V}(\mathrm{OH})\left(\mathrm{H}_{2} \mathrm{O}\right)\right]^{+}$and $\left[\mathrm{Cp}_{2} \mathrm{~V}(\mathrm{OH})_{2}\right]{ }^{13}$ Thus, it is anticipated that an aqueous solution of $\mathrm{Cp}_{2} \mathrm{VCl}_{2}$ would afford cationic vanadium species, which could react with dioxygen of air to produce radical species that would act as an initiator for polymerisation.

Accordingly, polymerisation reactions of styrene and MMA were carried out in air and we could isolate PS and PMMA with high molecular weights and low molecular weight distribution (table 5). In order to elucidate the effect of dioxygen we have carried out polymerisation of styrene in argon atmosphere and isolated PS in poor yield (14.4\%) with much lower molecular weight $\left(M_{w}=33,000\right)$ and higher molecular weight distribution $\left(M_{w} / M_{n}=2 \cdot 6\right)$. Dioxygen has been shown to increase induction time and reduce molecular weight of the polymer and thus acts as an inhibitor. ${ }^{18}$ However, the observed results clearly show that presence of dioxygen increases molecular weight and decreases molecular weight distribution dramatically. Polymerization reactions are completely inhibited by 4-hydroxy-2,2,6,6-tetramethylpiperidinyloxy free radical (4-hydroxy-TEMO) and 5,5-dimethyl-1-pyrroline $\mathrm{N}$-oxide (DMPO) indicating that the polymerisation proceeds through a radical mechanism.

The cyclic voltammetry of the oxidative scan (figure 3) of an aqueous solution of $\mathrm{Cp}_{2} \mathrm{VCl}_{2}$ containing SDS shows a quasi-reversible oxidative couple at $E_{1 / 2}=-0.603 \mathrm{~V}$ and a nearly reversible oxidative couple at $E_{1 / 2}=-0.350 \mathrm{~V}$ under argon atmosphere. These oxidative couples can be assigned to $\mathrm{V}^{\mathrm{V}} / \mathrm{V}^{\mathrm{IV}}$ couples of two V(IV) species generated in solution. It has been reported that cyclic voltammetry of an aqueous solution of $\mathrm{Cp}_{2} \mathrm{VCl}_{2}$ in the presence of $\mathrm{KCl}$ shows a quasi-reversible $\mathrm{V}^{\mathrm{IV}} / \mathrm{V}^{\mathrm{III}}$ reductive couple at $E_{1 / 2}=-0.472 \mathrm{~V} .{ }^{21}$ Thus, it is clear that, in the presence of SDS, the electrochemical behaviour of $\mathrm{Cp}_{2} \mathrm{VCl}_{2}$ completely changes and oxidation of $\mathrm{V}^{1 \mathrm{~V}}$ to $\mathrm{V}^{\mathrm{V}}$ is feasible.

The ESR spectral change observed for an aqueous solution of $\mathrm{Cp}_{2} \mathrm{VCl}_{2}$ containing $\mathrm{SDS}$ is shown in figure 4 . The spectral feature of a freshly prepared solution of $\mathrm{Cp}_{2} \mathrm{VCl}_{2}$, under argon atmosphere, can be explained as a superposition of 8 hyperfine $\left(A_{a v}=\right.$ $76 \mathrm{G}$ and $109 \mathrm{G}$ ) peaks (figure $4 \mathrm{a}$ ) of two species, $\left[\mathrm{Cp}_{2} \mathrm{~V}\left(\mathrm{H}_{2} \mathrm{O}\right)_{2}\right]^{2+}$ and $\left[\mathrm{Cp}_{2} \mathrm{~V}(\mathrm{OH})\left(\mathrm{H}_{2} \mathrm{O}\right)\right]^{+}$respectively. 

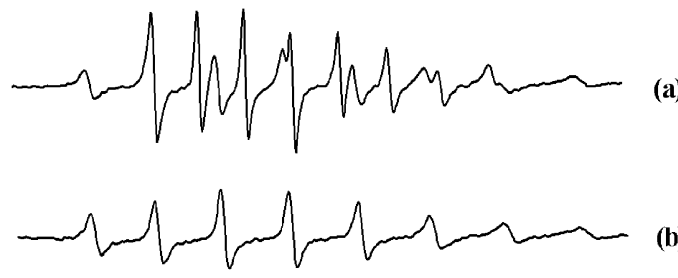

dpph

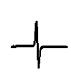

$$
3000
$$

$$
3200
$$

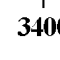

$3400 \quad 3600$

Figure 4. $\mathrm{X}$-band ESR spectra of $\mathrm{Cp}_{2} \mathrm{VCl}_{2}$. (a) Spectrum of $\mathrm{Cp}_{2} \mathrm{VCl}_{2}$ taken in aqueous SDS solution under argon atmosphere within 5 min. (b) Spectrum of (a) taken after 45 min under argon atmosphere. General conditions: temperature $=298 \mathrm{~K}$, microwave frequency $=9.85 \mathrm{GHz}$, microwave power $=0.64 \mathrm{~mW}$, modulation frequency $=$ $50 \mathrm{kHz}$, modulation amplitude $=4 \mathrm{G}$, receiver gain $=$ $1.59 \times 10^{5}$. Sweep width $=1000 \mathrm{G}$. Time constant $=$ $81.92 \mathrm{~ms}$. Conversion time $=655 \cdot 36 \mathrm{~ms}$.

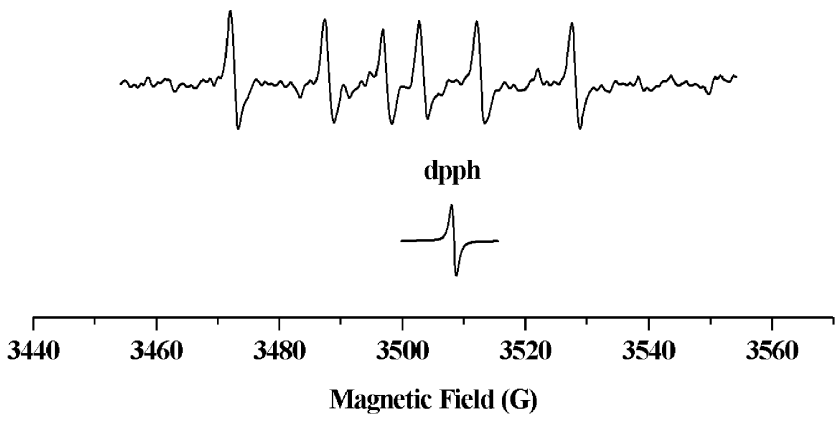

Figure 5. $\mathrm{X}$-band $\mathrm{ESR}$ spectrum of $\mathrm{Cp}_{2} \mathrm{VCl}_{2}$ taken in aqueous SDS solution in the presence of DMPO after exposure to air for $1 \mathrm{~h}$. General conditions: temperature = $298 \mathrm{~K}$, microwave frequency $=9.85 \mathrm{GHz}$, microwave power $=0.64 \mathrm{~mW}$, modulation frequency $=50 \mathrm{kHz}$, modulation amplitude $=0.5 \mathrm{G}$, receiver gain $=8.93 \times 104$. Sweep width $=100 \mathrm{G}$. Time constant $=55 \cdot 36 \mathrm{~ms}$. Conversion time $=163 \cdot 84 \mathrm{~ms}$.

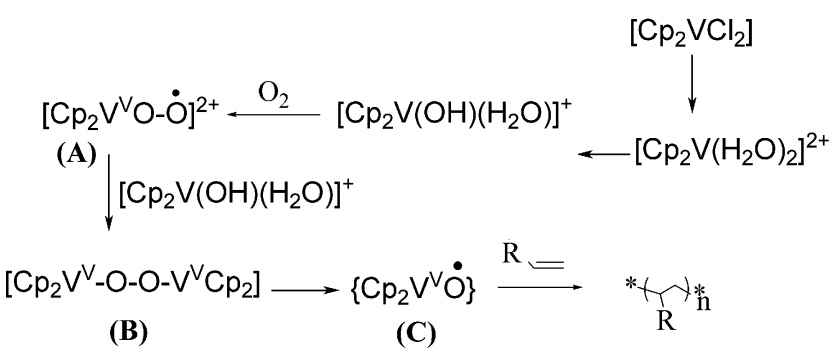

Scheme 3.
The solution on standing for about an hour shows an 8 line spectrum $\left(A_{a v}=109 \mathrm{G}\right)$ which may be due to $\left[\mathrm{Cp}_{2} \mathrm{~V}(\mathrm{OH})\left(\mathrm{H}_{2} \mathrm{O}\right)\right]^{+}$(figure $4 \mathrm{~b}$ ). The ESR experiments with DMPO as the spin trap were done to examine the formation of radical species during aerial oxidation of the aqueous solution of $\mathrm{Cp}_{2} \mathrm{VCl}_{2}$. When aerial oxidation of the aqueous solution of $\mathrm{Cp}_{2} \mathrm{VCl}_{2}$ was done in presence of DMPO, a typical 6-line spectrum $\left(A_{N}=15.34 \mathrm{G}, A_{H}{ }^{\beta}=9.30 \mathrm{G}, A_{H}{ }^{\alpha}=6.06 \mathrm{G}\right)$ (figure 5) of a DMPO trapped radical appeared.

A similar kind of ESR spectrum of DMPO trapped ${ }^{\circ}$ OMe radical has been reported recently. ${ }^{23}$ It is clear that the generated radical is neither $\mathrm{OH}^{\bullet}$ nor superoxide radical, as spin-trapped DMPO-OH gives a four-line spectrum and the observed values of $\mathrm{A}_{\mathrm{H}}{ }^{\alpha}$ and $\mathrm{A}_{\mathrm{H}}{ }^{\beta}$ are not the same as reported for the DMPO$\mathrm{OOH}$ radical. ${ }^{24}$ Thus it is clear that a new kind of radical species is generated upon interaction of aerial oxygen with an aqueous solution of $\mathrm{Cp}_{2} \mathrm{VCl}_{2}$ and we hypothesized it to be $\left({ }^{\circ} \mathrm{OV}^{\mathrm{V}} \mathrm{Cp}_{2}^{2+}\right)$. A similar kind of radical, $\left({ }^{\circ} \mathrm{OV}^{\mathrm{V}}\left(\mathrm{O}_{2}\right)_{2}^{+}\right)$, has been suggested as an intermediate in the reduction of $\left[\mathrm{VO}\left(\mathrm{O}_{2}\right)_{2}\right]^{-}$by $\mathrm{VO}^{2+}{ }^{25}$ Also, It may be noted that in the oxygen-dependent $\mathrm{Cp}_{2} \mathrm{~V}(\mathrm{acac})^{+}$initiated lipid peroxidation a similar inner sphere, electron transfer between vanadium(IV) and dioxygen has been suggested. ${ }^{21}$ Similar experiments with $\mathrm{VOSO}_{4}$ did not show formation of any radical species indicating that $\mathrm{VO}^{2+}$ does not have any interaction with DMPO. Based on the ESR experiments, a mechanism has been formulated and is shown in scheme 3. The first step is the hydrolysis of $\mathrm{Cp}_{2} \mathrm{VCl}_{2}$ to afford $\left[\mathrm{Cp}_{2} \mathrm{~V}(\mathrm{OH})\left(\mathrm{H}_{2} \mathrm{O}\right)\right]^{+}$, which coordinates dioxygen and an inner sphere electron transfer takes place to afford $\mathrm{V}(\mathrm{V})$ coordinated superoxo species, A, that reacts with another $\left[\mathrm{Cp}_{2} \mathrm{~V}(\mathrm{OH})\left(\mathrm{H}_{2} \mathrm{O}\right)\right]^{+}$ to give $\mu$-peroxo $\mathrm{V}(\mathrm{V})$ species, $\mathbf{B}$. The species $\mathbf{B}$ then undergoes homolytic cleavage to afford an oxoradical, ${ }^{\circ} \mathrm{OV}^{V} \mathrm{Cp}_{2}{ }^{2+}, \mathbf{C}$, which is responsible for initiating polymerisation.

\section{Conclusions}

Thus, an environmentally benign route to Hunsdiecker products have been developed. Also, it has been shown that in hydrolysis of $\mathrm{Cp}_{2} \mathrm{MCl}_{2}(\mathrm{M}=\mathrm{Ti}$, $\mathrm{V}$ or $\mathrm{Zr}$ ) commercially available early transition metal compounds, can be advantageously used as catalysts for aqueous polymerisation. Using these catalysts, high molecular weight polymers with low molecular weight distribution can be obtained. In contrast to the general notion that oxygen is an in- 
hibitor in polymerisation, it has been shown for the first time that oxygen can enhance polymerisation. Comparison with the $\mathrm{Cp}_{2} \mathrm{TiCl}_{2}$ and $\mathrm{Cp}_{2} \mathrm{ZrCl}_{2}$ catalysed homo- and co-polymerisation of styrene and methyl methacrylate, ${ }^{4}$ reported from this laboratory, shows that vanadium-catalysed polymerisation is fundamentally different. Whereas $\mathrm{Cp}_{2} \mathrm{VCl}_{2}$-catalysed polymerisation $^{22}$ proceeds via a radical mechanism, those catalysed by corresponding titanium and zirconium compounds proceed via insertion mechanism. It may be noted that time and again it has been emphasized in literature that the early transition metal organometallic compounds are highly moisture sensitive and thus, are not suitable as catalysts for aqueous polymerisation. However, it has been shown that the metal-cyclopentadienyl bond in $\mathrm{Cp}_{2} \mathrm{MCl}_{2}(\mathrm{M}=\mathrm{V}$, $\mathrm{Ti}$, or $\mathrm{Zr})$ compounds is quite stable $\mathrm{e}^{15}$ and in aqueous solution produces cationic species of the types $\left[\mathrm{Cp}_{2} \mathrm{M}\left(\mathrm{H}_{2} \mathrm{O}\right)_{2}\right]^{2+},\left[\mathrm{Cp}_{2} \mathrm{M}(\mathrm{HO})\right]^{+}$, and $\left[\mathrm{Cp}_{2} \mathrm{M}(\mathrm{OH})_{2}\right]$, depending upon the $\mathrm{pH}$ of the solution, while in lower $\mathrm{pH}$ the $\mathrm{M}-\mathrm{Cp}$ bond remains intact for days. It has been observed that the structural integrity of $\mathrm{Cp}_{2} \mathrm{~V}^{2+}$ ion is maintained even at higher $\mathrm{pH} .{ }^{12}$ In the present work as well as in our earlier works the stability of these cationic species has been exploited for their catalytic activity.

\section{Experimental}

\subsection{Sodium molybdate catalysed aqueous Hunsdiecker reaction}

When a suspension of $\alpha, \beta$-unsaturated aromatic carboxylic acid $(0.02 \mathrm{~mol})$ is stirred with $\mathrm{KBr}$ $(0.04 \mathrm{~mol})$ and $\mathrm{Na}_{2} \mathrm{MoO}_{4} \cdot 2 \mathrm{H}_{2} \mathrm{O}(0.001 \mathrm{~mol})$ in water $\left(5 \mathrm{~cm}^{3}\right)$ and $\mathrm{H}_{2} \mathrm{O}_{2}\left(15 \mathrm{~cm}^{3}, 0 \cdot 13 \mathrm{~mol}\right)$ is added dropwise at room temperature $\left(30^{\circ} \mathrm{C}\right)$, a rapid reaction takes place and the temperature rises to $80^{\circ} \mathrm{C}$ within $20 \mathrm{~min}$. The reaction mixture is stirred for farther $20 \mathrm{~min}$ and the product as well as the un-reacted acid are extracted with diethyl ether. The corresponding $\beta$-bromo-styrene are separated from the starting material by column chromatography in good yield.

\section{2 $\mathrm{Cp}_{2} \mathrm{MCl}_{2}(\mathrm{M}=\mathrm{Ti}, \mathrm{V}$, or $\mathrm{Zr})$ catalysed homo-} polymerisation of styrene and methylmethacrylate

All the polymerisation reactions were carried out under argon atmosphere as well as under aerobic conditions. No major difference could be observed in case of titanium and zirconium compounds. In the case of $\mathrm{Cp}_{2} \mathrm{VCl}_{2}$ catalysed polymerisation the polymerisation reactions were carried out under aerobic condition. A general procedure is described below.

$\mathrm{Cp}_{2} \mathrm{MCl}_{2}(0.0005 \mathrm{~mol})$ was suspended in water $(20 \mathrm{ml})$ and this suspension was stirred for about $1 \mathrm{~h}$, whereupon a clear solution was obtained. Sodium $n$-dodecyl sulphate (SDS) $\left(1.6 \times 10^{-3} \mathrm{~mol}\right)$ was dissolved in water $(80 \mathrm{ml})$. To this was added methylmethacrylate (MMA) or styrene $(0.05 \mathrm{~mol})$ and the whole were stirred for $1 \mathrm{~h}$. To the emulsified monomer solution was then added the aqueous solution of $\mathrm{Cp}_{2} \mathrm{MCl}_{2}$. The polymerisation mixture was then placed in an oil bath maintained at the desired temperature and the reaction mixture was stirred for required time period. The reaction was quenched by the addition of the emulsion to a mixture of methanol $(200 \mathrm{ml})$ and hydrochloric acid $(20 \mathrm{ml})$. The precipitated polymer was then filtered, washed repeatedly with methanol and dried in vacuo at ambient temperature. Finally, the polymer was extracted with hot water for $3 \mathrm{~h}$ and filtered to remove water soluble material. PMMA was purified by dissolution in acetone and re-precipitation with the addition of excess methanol. Polystyrene was extracted with refluxing acetone for $3 \mathrm{~h}$ to remove low molecular weight fraction of the polymer. The polymer was finally purified by dissolving it in toluene and precipitation by the addition of methanol and finally dried in vacuo.

\section{$4.3 \mathrm{Cp}_{2} \mathrm{TiCl}_{2}$ catalysed co-polymerisation of styrene and methylmethacrylate}

A typical polymerisation procedure is described below. A sample of $\mathrm{Cp}_{2} \mathrm{TiCl}_{2}(0 \cdot 1245 \mathrm{~g} ; 0.0005 \mathrm{~mol})$ was suspended in water $(20 \mathrm{ml})$ and this suspension was stirred for about $1 \mathrm{~h}$, where upon a yellow solution was obtained. Sodium $n$-dodecyl sulphate (SDS) $\left(1.6 \times 10^{-3} \mathrm{~mol}\right)$ was dissolved in water $(80 \mathrm{ml})$. To this styrene $(2.6 \mathrm{~g} ; 0.025 \mathrm{~mol})$ and methylmethacrylate $(2.5 \mathrm{~g} ; 0.025 \mathrm{~mol})$ was added. The monomers were emulsified by stirring for $1 \mathrm{~h}$. To the emulsified monomer solution was then added the aqueous solution of $\mathrm{Cp}_{2} \mathrm{TiCl}_{2}$. The reaction mixture was then placed in an oil bath maintained at the desired temperature and the reaction mixture was stirred for required time period. The reaction was quenched by the addition of the reaction mixture to a mixture of methanol and hydrochloric acid. The precipitated polymer was filtered, washed repeatedly with methanol and dried in vacuo at ambient temperature. The 
crude copolymer was then extracted with cyclohexane to remove polystyrene and with acetonitrile to remove poly (methylmethacrylate) homopolymers.

To further study the copolymerisation of styrene with methylmethacrylate, a set of four experiments was conducted. Different feed ratios of styrene and methylmethacrylate were employed and the copolymerisation reactions were quenched at low yields $(<10 \%)$. The copolymer composition was calculated by ${ }^{1} \mathrm{H}$ NMR and the reactivity ratio was determined by Finemann-Ross equation.

\section{Acknowledgements}

We thank the Department of Science \& Technology, Govt. of India, for financial support, and Prof G Sundararajan, Indian Institute of Technology, Chennai and Prof A Kumar, Indian Institute of Technology, Mumbai for the gel permeation chromatography results.

\section{References}

1. Lindström U M 2002 Chem. Rev. 1022751

2. (a) Qiu J, Charleux B and Matyjaszewski K 2001 Prog. Polym. Sci. 26 2083; (b) Held A F, Bauers M and Mecking S 2000 Chem. Commun. 301; (c) Held A and Mecking S 2000 Chem. Eur. J. 6 4623; (d) Bauers F M and Mecking S 2001 Macromolecules 34 1165; (e) Menders B, Sciandrone L, Hauk G L and Kristen M O 2001 Angew. Chem., Int. Ed. 404006

3. (a) Bhattacharjee M 1992 Polyhedron 11 2817; (b) Bhattacharjee M, Ganguly S and Mukherjee J 1995 J. Chem. Res. Synop. 80; (c) Bhattacharjee M and Mukherjee J 1995 J. Chem. Res. Synop. 238; (d) Mukherjee J, Ganguly S and Bhattacharjee M 1996 Indian J. Chem., A35 471

4. (a) Bhattacharjee M and Patra B N 2004 J. Organomet. Chem. 689 1091; (b) Bhattacharjee M and Patra B N 2004 Polymer 45 3111; (c) Patra B N and Bhattacharjee M 2005 J. Polym. Sci. A43 3797; (d) Patra B N and Bhattacharjee M 2005 J. Polym. Sci. A43 3707
5. Johnson R G and Ingham K R 1956 Chem. Rev. 56 219

6. Naskar D, Chowdhury S and Roy S 1998 Tetrahedron Lett. 39699

7. (a) Mimoun H, Mignard M, Brechot $\mathrm{P}$ and Saussine $\mathrm{L}$ 1986 J. Am. Chem. Soc. 108 3711; (b) Mimoun H, Saussine L, Daire E, Postal M, Fischer J and Weiss R 1983 J. Am. Chem. Soc. 105 3101; (c) Bhattacharjee M, Chettri S K, Chaudhuri M K, Islam N S and Roy Barman S 1993 J. Mol. Catal. 78143

8. Vilter H 1984 Phytochemistry 231387

9. Sinha J, Layek S, Mandal G C and Bhattacharjee M 2001 Chem. Commun. 1916

10. Nardello V, Marko J, Vermeersch G and Aubry J M 1995 Inorg. Chem. 344950

11. Mecking S, Held A and Bauers F M 2002 Angew. Chem. Int. Ed. 41544

12. Kaminsky W and Arndt M 1997 Adv. Polym. Sci. 127 143

13. (a) Toney J H and Marks T J 1985 J. Am. Chem. Soc. 107 94; (b) Toney J H, Brock C P and Marks T J 1986 J. Am. Chem. Soc. 1087264

14. Shafir C A, Reeder C L and Arnold J 2003 Organometallics 223357

15. Cunningham M F, Geramita K and Ma J W 2000 Polymer 405385

16. Jensen T R, Yoon S C, Dash A K, Luo L and Marks T J 2003 J. Am. Chem. Soc. 12514483

17. Fineman M and Ross S D 1950 J. Polym. Sci. 5259

18. Bajpai S and Srivastava A K 2001 J. Appl. Polym. Sci. 802774

19. (a) Döbler C, Mehltretter G and Beller M 1999 Angew. Chem., Int. Ed. 38 3026; (b) Khenkin A M and Neumann R 2000 Angew. Chem., Int. Ed. 394088

20. Kosugi M, Hikichi S, Akita M and Moro-oka Y 1999 Dalton Trans. 1369

21. Kotchevar A T, Ghosh P, DuMez D D and Uckun F M 2001 J. Inorg. Biochem. 83151

22. Patra B N and Bhattacharjee M 2006 J. Polym. Sci. A44 2749

23. Jones C M and Brukitt M J 2003 J. Am. Chem. Soc. 125 6946

24. Clement J L, Ferre N, Siri D, Karoui H, Rockenbauer A and Tordo P 2005 J. Org. Chem. 701198

25. Ravishankar H N and Ramasarma T 1995 Arch. Biochem. Biophys. 316 319; (b) Ramasarma T and Ravishankar H N 2005 Biochem. Biophys. Acta 172230 